En la sociedad mexicana del siglo XIX, todavía configurada por una cosmovisión católica, el nuevo sistema de referencias que se construyó en torno al liberalismo fue una mutación global que transformó las relaciones de la sociedad y de los individuos, tanto en la forma de asociación como en las instituciones, los valores y los comportamientos. A partir de los cambios introducidos por el pensamiento liberal, la nación se concebiría como una asociación de individuos, de ciudadanos, en contraste con la visión corporativa, es decir, de cuerpos o grupos, que había privado hasta entonces. ${ }^{1}$

Así, la difusión del liberalismo, con el nacimiento de un Estado nacional, se gestó en medio de grandes contradicciones que enfrentaron la identidad con el pasado - que recurría a elementos como la tradición hispana e indígena y el catolicismo como lazo de unión - con la necesidad de una modernidad que apelaba al capitalismo, la libertad en todos los órdenes, incluida la de creencias y el individualismo. En tiempos "de contradicción y no de síntesis", ambas visiones del mundo se enfrentaron a medida que se difundió el pensamiento liberal en América Latina, y específicamente en México. ${ }^{2}$

En ese sentido, una vez que los actores políticos se fueron identificando con el pensamiento liberal, o lo rechazaron, esta nueva forma de concebir lo político, que incluyó lo religioso, se convirtió en un problema de índole pública. E1 hecho de pretender relegar a la religión al ámbito privado, como lo proponían los simpatizantes del liberalismo, generó una inconformidad que llevaría a la ruptura total entre éstos y los defensores de la Iglesia católica, conocidos tradicionalmente como conservadores.

En torno a este tema se ha visto que la reacción generalizada de la Iglesia frente al liberalismo fue de rechazo y finalmente de ruptura. Hasta la Reforma, no sólo la

1 François Xavier Guerra, Los espacios públicos en Iberoamérica. Ambigüedades y problemas. Siglos XVIII-XIX, p. 12.

2 Para un análisis de la transformación de la posición de la Iglesia en América Latina durante la época decimonónica, vid. Enrique Dussel, "La Iglesia en el proceso de organización nacional y de los Estados en América Latina (1830-1880)", en Álvaro Matute, Evelia Trejo, Brian Connaughton (coords.) Estado, Iglesia y sociedad en México en el siglo XIX, pp. 63-80. 
3 Brian Connaughton, Dimensiones de la identidad patriótica. Religión, política y regiones en México. Siglo XIX, p. 223.

4 Rubén Ruiz Guerra, "Religiosidad moderna e identidad: algunas consideraciones a partir de la experiencia mexicana decimonónica", en Cuadernos Americanos, núm. 70. julio-agosto 1998. pp. 187-188. visión de algunos individuos, sino también la que se plasmó en diversos documentos políticos, identificó a la "mexicanidad" con el catolicismo, es decir, ser ciudadano mexicano equivalía a ser católico. Esto obligó a que este tema se volviera asunto nodal en la erección del nuevo Estado-nación, y la definición de las relaciones entre la Iglesia y el Estado se convirtió en tema central en cuanto a la manera de concebir a la patria. ${ }^{3}$

El conflicto entre la Iglesia y el Estado que se desató a mediados del siglo XIX se exacerbó después del triunfo de la revolución de Ayutla, cuando comenzó a debatirse abiertamente en el Congreso Constituyente de 1856 el papel que se daría en adelante a la institución eclesiástica y que quedaría plasmado en la Carta Constitucional de 1857. Ese documento suscitó airadas reacciones del clero, que instrumentó una ofensiva basada en la identificación que los mexicanos de entonces tenían con la religión heredada por sus padres y que se consideraba un lazo de unión entre los habitantes de una nación por demás heterogénea. Dicha oposición se fue haciendo más enconada a medida que la Iglesia sintió que su lugar en el ámbito público quedaba cada vez más relegado, y la manifestación máxima de este conflicto fue la guerra que se desató por la intransigencia de los defensores de la Iglesia frente a quienes buscaban que su influencia se limitara al espacio privado.

En el lado opuesto del espectro, desde la perspectiva de los políticos liberales, la búsqueda de la modernidad política y económica implicó un "replanteamiento en el universo de lo religioso" que pretendía construir una identidad diferente "estructurada [...] a la luz de la razón". Muchos de quienes buscaban que la religión y la Iglesia ocuparan un lugar distinto en la sociedad cuestionaron los abusos del clero, así como el fanatismo, y pugnaron por una mayor moralidad de la sociedad. ${ }^{4}$ Entre sus objetivos se hallaban la promoción del capitalismo, la subordinación de la Iglesia y el ejército (hasta entonces autónomos y privilegiados) a la autoridad civil, el establecimiento de la igualdad jurídica y una eliminación general de las limitaciones que las corporaciones habían fijado al individuo. Ese programa liberal incluía una reducción de la riqueza de la Iglesia a un nivel que le bastara para desem- 
peñar sus funciones, y tolerancia religiosa, como señuelo para el comercio exterior y la inmigración. ${ }^{5}$

Entre quienes pugnaban por poner en práctica estos principios comenzó a destacar desde muy joven Benito Juárez, originario de Oaxaca y quien muy pronto dio muestras de sus inquietudes intelectuales. En sus propias palabras, decidió seguir la carrera eclesiástica "por la que sentía una instintiva repugnancia" con tal de recibir una educación que de otra forma le estaba vedada "por ser pobre". ${ }^{6}$ En ese sentido, la instrucción recibida por Juárez en una escuela confesional - porque no había más opciones - lo 1levó más adelante a cuestionar la influencia del clero en la educación, y fue un acicate para su idea de la necesaria libertad educativa que debía existir en una nación liberal y moderna. ${ }^{7}$

En la época que Juárez llevó a cabo sus estudios, que en primera instancia serían de Gramática Latina y Teología Moral, "se habían ya realizado grandes acontecimientos en la nación", como la consumación de la independencia y la promulgación de la Constitución de 1824, a la que Juárez calificó de centralista "porque en la nueva carta se incrustaron la intolerancia religiosa, los fueros de las clases privilegiadas [...] y otros contraprincipios que nulificaban la libertad y la federación que se quería establecer". ${ }^{8}$ Para Benito Juárez, una de las mayores críticas que podían hacerse a la Carta Constitucional de 1824 era, precisamente, que no incluyó en sus postulados la tolerancia religiosa, uno de los elementos centrales en el pensamiento liberal que fue considerada como "la piedra fundamental de todas las libertades y derechos del hombre". ${ }^{9}$ Era tan grave esa omisión, que eliminar esa libertad fundamental había sido el origen de las constantes convulsiones que la nación seguiría sufriendo mientras no se hiciera efectiva "la igualdad de derechos y obligaciones entre todos los ciudadanos y entre todos los hombres [...] sin fueros, sin monopolios y sin odiosas distinciones". ${ }^{10}$

En Oaxaca, durante los años posteriores a la promulgación de la Constitución de 1824, la medida más importante para desembarazarse de la influencia del clero, en palabras de Benito Juárez, fue "el establecimiento de un Colegio Civil que se denominó Instituto de Ciencias y
5 Robert J. Knowlton, Los bienes del clero y la Reforma mexicana, 1856-1910, pp. 39-40.

6 Benito Juárez, "Apuntes para mis hijos", en Antología de Benito Juárez, apuntes, selección y notas de Jorge L. Tamayo, p. 5.

7 Al respecto, Silvestre Villegas Revueltas afirma que "muchos liberales que concurrieron a escuelas confesionales [...] reaccionaron con gran virulencia ante [la Iglesia] esta institución que conocian y que les había dejado una huella indeleble..." Vid. Silvestre Villegas Revueltas, El liberalismo moderado en México. 1852-1864. p. 61.

8 Juárez, Apuntes... op. cit., pp. 8-9.

9 José Ma. Vigil, "La Reforma”, en México a través de los siglos, p. 172. 10 Juárez, Apuntes... op. cit., p. 9. 
11 ldem.

12 Ibid., p. 11.

13 Ibid., p. 14.

14 Ibid., p. 21.

Artes [...] destinado a la enseñanza de la Juventud...". ${ }^{11}$ En 1828 Juárez dejó el seminario en donde, a decir de él mismo, se "fastidió" de estudiar teología "por lo incomprensible de sus principios [y por su] natural deseo de seguir otra carrera distinta de la eclesiástica" y entró al Instituto a estudiar jurisprudencia. Según Juárez, todos los catedráticos de ese nuevo establecimiento eran del Partido Liberal y "porque el clero conoció que aquel nuevo plantel de educación, donde no se ponían trabas a la inteligencia para descubrir la verdad, sería en lo sucesivo [...] la ruina de su poder basado sobre el error y las preocupaciones, le declaró una guerra sistemática y cruel...". ${ }^{12}$

Así, en los años posteriores a que Juárez obtuvo su título de abogado, y después de desempeñar un corto tiempo el puesto de magistrado interino de la Corte de Justicia del estado de Oaxaca, se dedicó a la abogacía. Entonces, según Juárez, el clero se hallaba todavía "en pleno goce de sus fueros y prerrogativas y su alianza estrecha con el poder civil, le daba una influencia casi omnipotente. ${ }^{13} \mathrm{Es}$ evidente que las acciones que el futuro presidente iba a emprender más adelante para limitar la influencia y el poder de la Iglesia católica tuvieron su origen en sus años de juventud, cuando pudo experimentar en carne propia las limitaciones que imponía una educación basada principalmente en los dogmas y que no permitía la libertad de pensamiento.

Benito Juárez fue gobernador interino de Oaxaca desde el 29 de noviembre de 1847 hasta el 12 de agosto de 1848 , fecha en que fue reelecto para el segundo periodo constitucional que concluyó en agosto de $1852 .{ }^{14}$ Durante la presidencia de Antonio López de Santa Anna, estuvo exiliado en Nueva Orleáns y a la caída del veracruzano, después de la revolución de Ayutla, Juan Álvarez quedó al frente del Ejecutivo y nombró a Juárez Ministro de Justicia e Instrucción Pública. Fue precisamente en esa coyuntura cuando se tomó la primera medida de la Reforma promovida por Benito Juárez y llamada por ello Ley Juárez. Ésta fue emitida el 23 de noviembre de 1855 y además de establecer una Suprema Corte de Justicia, así como tribunales civiles y penales, suprimió parcialmente los fueros de las corporaciones, por lo que queda- 
ron abolidos todos los tribunales especiales, con excepción de las cortes eclesiásticas y militares. Los tribunales eclesiásticos, entonces, sólo tendrían jurisdicción sobre los delitos cometidos por miembros del clero, pero éstos podían renunciar al fuero y ser juzgados en un tribunal civil; lo más importante era que la ley ponía a los laicos fuera de la jurisdicción de los tribunales de la Iglesia. Como era de esperarse, "la oposición del clero a la Ley Juárez fue inmediata y persistente". ${ }^{15}$ Juárez dice al respecto que esta ley fue "la chispa que produjo el incendio de la reforma que más adelante consumió el carcomido edificio de los abusos y preocupaciones; fue en fin el cartel de desafío que se arrojó a las clases privilegiadas". ${ }^{16}$

A partir de enero de 1856 Juárez ejerció nuevamente el cargo de gobernador de Oaxaca y en ese momento marcó claramente su distancia con respecto a la Iglesia católica; en contra de la costumbre de entonces de que el nuevo gobernador de un estado fuera a la Catedral y escuchara un Te Deum en su honor, decidió no asistir por su convicción de que "los gobernantes de la sociedad civil no deben asistir como tales a ninguna ceremonia eclesiástica, si bien como hombres pueden ir a los templos a practicar los actos de devoción que su religión les dicte. Los gobiernos civiles no deben tener religión porque siendo su deber proteger imparcialmente la libertad que los gobernados tienen de seguir y practicar la religión que gusten adoptar, no llenarían fielmente su deber si fueran sectarios de alguna [...]" Esta decisión de Juárez es una muestra de que él concebía la práctica religiosa como una cuestión de conciencia, que tenía que ver con la relación privada que se establece entre el ser humano y la divinidad. La autoridad civil no tenía por qué ser sancionada mediante un acto de carácter religioso. ${ }^{17}$

Mientras Juárez desempeñaba sus funciones como gobernador de Oaxaca, de abril a junio de 1856 apareció una nueva serie de medidas legislativas entre las que se encontraba la Ley Lerdo o de desamortización de bienes raíces civiles y eclesiásticos. De acuerdo con ésta, toda finca administrada por cualquier corporación se adjudicaba en propiedad a los arrendatarios por el valor equivalente a la renta que pagaban. Además, incapacitaba a las mismas corporaciones a adquirir o administrar bienes 
18 Francisco Morales, "Las Leyes de Reforma y la respuesta de los obispos", en Patricia Galeana (comp.), Relaciones Estado-Iglesia. Encuentros y desencuentros. p. 73.

19 Benito Juárez, Apuntes... op. cit., ..., p. 35. 20 Morales, op. cit., pp. 77-78.

21 Benito Juárez, carta dirigida desde Oaxaca a Matías Romero, el 22 de septiembre de 1857, en Antología de Benito Juárez..., p. 70.

22 Patricia Galeana, "Clericalismo y soberanía", en Patricia Galeana (comp.), Relaciones... op. cit., p. 97. raíces. ${ }^{18} 1857$ fue un año significativo porque entró en vigor la nueva Constitución que incluyó las leyes antes mencionadas y el mismo Juárez afirma que la puso inmediatamente en práctica "principalmente en lo relativo a la organización del Estado", ya que temía un motín en la ciudad de México por los polémicos principios "de libertad y de progreso" incluidos en la nueva Carta Constitucional. ${ }^{19}$

Tal como lo temía Juárez, la promulgación del documento constitucional enfrentó a los liberales y a la Iglesia, ya que dicha institución consideró que el Estado invadía campos que le habían pertenecido tradicionalmente. De esta manera, la Iglesia adoptó un concepto relativo a la conformación de un Estado moderno, la soberanía, para definirse como "sociedad perfecta", tal y como se autodefinía el Estado. La legitimación jurídica de esta soberanía eclesial era la jurisdicción papal, que apoyada en la infalibilidad pontificia en materia doctrinal, establecía que la independencia de la Iglesia frente a cualquier otro poder sería absoluta. ${ }^{20}$ Así, a partir de medidas que desde las filas eclesiásticas se veían como atentatorias contra la independencia de la misma institución, los liberales siguieron adelante como lo muestra la frase de Juárez en esa coyuntura: "jamás volveremos atrás como lo desean los enemigos de la libertad". ${ }^{21}$ La guerra que se desató por la radicalización de las posiciones de liberales y conservadores, estos últimos a nombre de la religión y de la Iglesia, "fue cruenta y al calor de ésta se promulgaron las Leyes de Reforma, mediante las cuales se logró separar los asuntos eclesiásticos y religiosos de los civiles y políticos", 22 tal como Juárez había pretendido desde que tomó la primera medida para limitar los privilegios del clero. En el momento en que se dieron a conocer dichas leyes Benito Juárez era presidente de la República, función que asumió en su calidad de Presidente de la Suprema Corte después del golpe de Estado del presidente moderado Ignacio Comonfort en 1858, cuando se polarizaron todavía más las posiciones políticas por la obligación de jurar la nueva Constitución.

De estas leyes, la más importante por lo que toca a los bienes eclesiásticos fue la Ley de Nacionalización del 12 de julio de 1859, que, como su nombre 1o indica, decretó 
la nacionalización de todos los bienes de las corporaciones; también se incluyó una ley del registro civil, una ley del matrimonio civil, un decreto que redujo el número de festividades religiosas, un decreto de secularización de cementerios y la ley de libertad de cultos religiosos. ${ }^{23}$ Esta última se había tratado de poner en práctica desde las primeras décadas posteriores a la independencia y se consideró fundamental en un estado moderno, ya que implicaba que cada persona podría profesar la religión que en conciencia decidiera.

Según Robert Knowlton, los liberales no se ponían de acuerdo en el momento oportuno de tomar medidas extremas contra la Iglesia, como lo fue la legislación reformista. En ese sentido, Benito Juárez y Melchor Ocampo, aunque "muy interesados en realizar la Reforma que privaría a la Iglesia de sus riquezas y de su tutela moral sobre el Estado, deseaban alcanzar esta meta sin herir en exceso los sentimientos religiosos del país. Pensaban que el momento apropiado para emitir las leyes sería cuando se hubiese obtenido o asegurado el triunfo militar, porque la Iglesia estaba tratando de convertir el conflicto civil en una guerra de religión". ${ }^{24}$ Sin embargo, las medidas se tomaron en medio del conflicto armado y su intención fue, según los mismos reformistas, limitar la influencia de la Iglesia y detener los abusos de una institución que había heredado privilegios y prerrogativas desde la época colonial. ${ }^{25}$

La sociedad mexicana de mediados del siglo XIX estaba tan polarizada, que a partir de 1858 coexistieron dos gobiernos en México: el liberal, con Benito Juárez a la cabeza, y que se estableció en Veracruz, y el conservador, con los generales Félix Zuloaga y Miguel Miramón en la ciudad de México. En 1861, al término de la guerra, Juárez regresó a la capital y su primer acto de gobierno fue la expulsión de todos los miembros de la Iglesia que habían participado en la guerra, así como de los representantes diplomáticos que intervinieron en la política nacional. Se reinstaló el Congreso y Juárez fue elegido presidente constitucional.

Frente a las dificultades financieras del gobierno liberal, Juárez tomó la decisión de suspender el pago de la deuda exterior, lo que dio origen a la intervención france
$23 \mathrm{El}$ texto completo de las Leyes de Reforma se puede consultar en Felipe Tena Ramírez, Leyes fundamentales de México,1808-1999, pp. 630-667.

24 Knowlton, op. cit., p. 99.

25 Benito Juárez, Miguel Lerdo de Tejada, Manuel Ruiz, Melchor Ocampo, "Justificación de las Leyes de Reforma", 7 de julio de 1859 , en Antología..., op. cit., pp. 80-83. 
26 Patricia Galeana, "Clericalismo... op. cit.," pp. 104-105.

27 Antonia Pi-Suñer, "Sebastián Lerdo de Tejada y su política frente a la Iglesia católica", en Galeana, Relaciones...op. cit., pp. 127-130.

28 Knowlton, op. cit., pp. 230231. sa y al imperio de Maximiliano de Habsburgo, apoyado por los grupos conservadores que confiaban en que un gobierno con un príncipe católico regresaría a la Iglesia sus privilegios perdidos. No obstante, las relaciones entre el segundo Imperio mexicano y la Iglesia católica fueron muy desafortunadas porque el emperador, tal como 1o habían hecho Juárez y los liberales, decretó la libertad de cultos y la validez de la nacionalización de bienes eclesiásticos, lo que fue un golpe terrible para la institución romana. A la postre, esta actitud de Maximiliano lo llevó a perder el apoyo de la Iglesia y de los conservadores, por lo que la caída del imperio fue inevitable. ${ }^{26}$

Con el triunfo de las fuerzas republicanas frente a la intervención francesa, y después del fusilamiento de Maximiliano de Habsburgo, Benito Juárez regresó a la ciudad de México al frente de un fortalecido Estado nacional mexicano que había logrado imponerse sobre un ejército invasor, y sobre la institución más poderosa hasta entonces, la Iglesia católica. En el periodo que va del inicio de la República Restaurada hasta la muerte de Juárez en 1872, el conflicto entre Estado e Iglesia quedó relegado a segundo término, e incluso hay quien afirma que se emprendió una política de conciliación que incluyó la propuesta, mediante cambios constitucionales, de otorgar el derecho al voto a los eclesiásticos, medida que aunque no prosperó, puso en evidencia la intención presidencial de suavizar las acciones contra la Iglesia y el clero. Frente a la oposición política en el Congreso y los ataques de la prensa liberal, Juárez toleró la desobediencia clerical a las Leyes de Reforma, lo que le dio cierta tranquilidad respecto a los conflictos con la Iglesia católica. ${ }^{27}$ De este modo, en medio de las continuas dificultades de la nacionalización - uno de tantos problemas graves a los que se enfrentaba el gobierno- el presidente Benito Juárez falleció súbitamente en julio de 1872. Así desapareció del escenario el hombre que durante tanto tiempo fue "símbolo de Reforma, Constitución y ley [...]". ${ }^{28}$ 


\section{CONSIDERACIONES FINALES}

El liberalismo fue la concepción política que logró consolidar al Estado mexicano. Fue aplicado de manera vertical por una élite antipopular que trató de establecer un proyecto de gobierno desde arriba y Juárez respondió a ese modelo autoritario, pero en una época tan llena de dificultades, y frente a una oposición tan radical como el pensamiento de los liberales, fue la única forma de convertir a México en un Estado nacional. ${ }^{29}$ Por otra parte, la mayoría de los políticos liberales decimonónicos fueron anticlericales, es decir, combatían la acción política del clero, pero no fueron antirreligiosos. El mismo Juárez se casó por la Iglesia y bautizó a sus hijos. Así, lo que se quiso evitar fue la injerencia de los sacerdotes en asuntos ajenos al culto religioso, y no la práctica misma de la religiosidad. ${ }^{30}$ Este enfrentamiento, entonces, no surgió por el deseo de atacar la religión, sino porque los liberales pensaban que la Iglesia era un obstáculo para la modernización del país.

En ese sentido, Jean Meyer afirma que la Iglesia católica, y los católicos, se levantaron "contra el Estado liberal que pretendía despojarla de lo que, sin serle propio, había sido suyo durante siglos - el estado civil, la asistencia, la educación-[...] Así, radicalizaron al liberalismo, a los liberales, y aceleraron, de manera involuntaria, la laicización de las instituciones religiosas que culminó con la separación de la Iglesia y el Estado". ${ }^{31}$

Es evidente que el enfrentamiento que se suscitó entre liberales y conservadores en la época de la Reforma, polarizó las posiciones y contribuyó a que ambos grupos dieran forma a un pensamiento que era el fruto de la sensación de estar acorralados por el avance de sus opositores. Unos no hubieran sido sin los otros, por lo que se puede afirmar que conservadores y liberales de todas las tendencias ayudaron a la gestación de su propio pensamiento, y más tarde a la radicalización del mismo. Es decir, podríamos preguntarnos si la crisis fomenta el radicalismo, o si éste desata la crisis. Es posible que se trate de un problema circular, ya que los extremos se tocan. ${ }^{32}$

Sin embargo, una vez que el triunfo liberal fue inobjetable, durante el periodo conocido como Repúbli
29 Patricia Galeana, Benito Juárez, el indio zapoteca que reformó México, p. 110. (Biblioteca lberoamericana).

30 Patricia Galeana,

Clericalismo... op. cit., p. 97.

31 Jean Meyer, "Para una historia política de la religión, para una historia religiosa de la política", en Metapolítica, marzo-abril 2002, pp. 36-37.

32 Guadalupe Gómez-Aguado y Adriana Gutiérrez Hernández, "El pensamiento conservador en los periódicos La Cruz y El Pájaro Verde: definición y transformación en tiempos de crisis", Erika Pani (coord.), Conservadurismos $y$ derechas en México, siglos $X I X$ y $X X$. En prensa. 
ca Restaurada, la actitud de Benito Juárez, como uno de los representantes del pensamiento político liberal más radical, fue de conciliación y de búsqueda de consensos, lo que implica que nunca fue antirreligioso, sino simplemente en su concepción de un Estado liberal y moderno, la Iglesia debía ser relegada al ámbito privado.

Todos los momentos que caracterizan el avance liberal a lo largo del siglo xix son una manifestación de los cambios que se suscitaron a partir de la difusión de los conceptos liberales y con ello la nueva concepción del individuo y de su papel en una sociedad laica en la cual la Iglesia ya no ocuparía un papel preponderante dentro de la esfera del poder público. Entonces, la única forma de crear un México moderno, basado en el concepto liberal de Estado, era rompiendo con los defensores de la religión $\mathrm{y}$, en ese sentido, no había forma de evitar las rupturas y los enfrentamientos que caracterizaron gran parte de la época decimonónica y de los cuales Benito Juárez fue un protagonista de excepción.

BIBLIOGRAFÍA

Antología de Benito Juárez, apuntes, selección y notas de Jorge L. TAMAYO. México, UNAM, 1972. (Biblioteca del Estudiante Universitario, 99).

Connaughton, Brian, Dimensiones de la identidad patriótica. Religión, política y regiones en México. Siglo XIX. México, UAM, Miguel Ángel Porrúa, 2001.

Dussel, Enrique, "La Iglesia en el proceso de organización nacional y de los Estados en América Latina (1830-1880)", en Álvaro Matute, Evelia Trejo, Brian Connaughton (coords.) Estado, Iglesia y sociedad en México en el siglo XIX. México, UnAm, Miguel Ángel Porrúa, 1995, pp. 63-80.

Galeana, Patricia, Benito Juárez, el indio zapoteca que reformó México. México, Anaya, 1988, p. 110. (Biblioteca Iberoamericana).

GaleanA, Patricia, "Clericalismo y soberanía”, en Patricia GALEANA (comp.), Relaciones Estado-Iglesia. Encuentros y desencuentros. México, Archivo General de la Nación, Secretaría de Gobernación, 2001, pp. 93-111. 
Gómez-AguAdo, Guadalupe y Adriana Gutiérrez HerNÁNDEZ, "El pensamiento conservador en los periódicos La Cruzy E1 Pájaro Verde: definición y transformación en tiempos de crisis", en Érika PANI (coord.), Conservadurismos y derechas en México, siglos XIX y XX. En prensa.

GUERRA, François Xavier, Los espacios públicos en Iberoamérica. Ambigüedades y problemas. Siglos XVIII-XIX. México, Centro Francés de Estudios Mexicanos y Centroamericanos, FCE, 1998.

Knowlton, Robert J., Los bienes del clero y la Reforma mexicana, 1856-1910. México, FCE, 1985.

Meyer, Jean, "Para una historia política de la religión, para una historia religiosa de la política", en Metapolítica, marzo-abril 2002, pp. 32-46.

Morales, Francisco, "Las Leyes de Reforma y la respuesta de los obispos", en Patricia GALEANA (comp.), Relaciones Estado-Iglesia. Encuentros y desencuentros. México, Archivo General de la Nación, Secretaría de Gobernación, 2001, pp. 67-91.

PI-SuÑER, Antonia, "Sebastián Lerdo de Tejada y su política frente a la Iglesia católica", en Patricia GALEANA (comp.), Relaciones Estado-Iglesia. Encuentros y desencuentros. México, Archivo General de la Nación, Secretaría de Gobernación, 2001, pp. 127-137.

RUIz GUERRA, Rubén, "Religiosidad moderna e identidad: algunas consideraciones a partir de la experiencia mexicana decimonónica", en Cuadernos Americanos, núm. 70, julio-agosto 1998, pp. 185-196.

Tena Ramírez, Felipe, Leyes fundamentales de MéxiCo,1808-1999, México, Porrúa, 1999.

Vigil, José Ma., "La Reforma" en México a través de los siglos, México, Cumbre, 1987. t. XIV.

Villegas Revueltas, Silvestre, El liberalismo moderado en México. 1852-1864. México, UNAM, 1997. 
